\title{
Las marcas país
}

\author{
Simon Anholt ${ }^{\star}$
}

Las marcas pais no existen. Son sólo un mito, y un mito bastante peligroso.

La sola idea de que a un país (o ciudad, o región se le pueda "poner marca", de la misma forma en que una empresa "le pone marca" a sus productos y servicios, es tan incitil como absurda. En los doce años transcurridos desde que acuñé el término "marca país" no he visto un ápice de evidencia, un solo estudio bien hecho, que demuestre que los programas de marketing comunicacional, los slogans o los logos hayan jamis alterado la percepcion internacional de un determinado lugar.

Es más, existe evidencia que apunta exactamente a lo contrario: entre el 2005, año en que lanzamos el Índice Anholt de Marcias País y el estudio que hicimos el último trimestre del ano pasado, no hemos detectado la más mínima correlación entre gasto en "campanas de imagen" y cambios en la percepción de un país. De hecho. varios paises que no ban hecho ninguna actividad especial de marketing más allá de las habituales para promover el turismo y la inversion han visto mejorar notablemente su imagen, en tanto otros que han gastado ingentes sumas en campanas de publicidad y relaciones públicas han visto su imagen internacional mantenerse estática e incluso empeorar.

Mís correcto seria decir yue las "marcas país" son el problema, no la solucion. Es la opinión pública la que catalogia a un país. 1)icho de otra forma, es la opinión pública la que reduce a los países a los estereotipos precarios, simplistas, destasados e inmerecidos que tanto daño hacen en clantexto de un mundo globalizado y es tarea de los gobicrnos combatir esa tendencia de la opinión pública internacional. los gobiernos deben ayudar al resto del mundo a conocer la realidad, complejidad, riqueza y' diversidad de sus

Asesor del Ciobicrno hritinico, creador del el Índice Anholt de Marcas País. 
países, sus pueblos, sus paisajes, su historia, su patrimonio, sus productos y sus recursos. En otras palabras, deben hacer lo posible por impedir que estos se conviertan en meras marcas.

Descle 1996, año en que acuñé el término "marca país", la idea ha crea(lo una cierta expectación en el sector publico debido a la tentadora pero ilusoria perspectiva de poder arreglar rapidamente una imagen nacional decarda o francamente negativa. Muchos gobjernos, la mayoría de los consultores y hasta algunos académicos insisten en aplicar la ingenua y superficial figura de la "marca lugar", lo que en realidad no es más cue identidad corporativay marketing comunes y corrientes, solo que, en lugar de un banco o una zapatilla, el producto es un pars, una ciudad o luna region.

La combinación de los términos "marca" "y "pás" tiene tanta resonancia porcuc conlleva una verdad importante: que la imagen de un lugar es fundamental para su progresoy prosperidad. lise es el argumento de fondo. Hoy en día, el mundoes un solo sran mercado. El rápido avance de la globalizacion ha hecho que cada pais. ciudad y regiom deban competir entre si por llevarse una tajada de las transacciones comerciales, sociales, políticas y' culturales que se realizan en el mundo. Fin un entorno así, como en cualquier mercado atestado, la imagen de marcia se convicrte en un factor esencial: es el atajo para llegar a una decision informada. El efecto de la imagen pais es evidente. l.os paises, ciudades y regiones que han tenido la suerte o la virtud de adquirir buena reputación descubren que todo lo que necesitan hacer en la escena mundial se les hace más fácil. Su marca va por delante, abriendo puertas y creando confianza, respetoy la expectativa de calidad, competencia y probidiad.

Por su parte, los lugares conocidos por ser pobres, incultos, atrasados, peligrosos o corruptos encuentran que todo lo que tratan de hacer a nivel exterior se les hace más dificil y sus ciudadanos se encuentran con gue deben demostrar que nocorresponden al estereotipo nacional. Comparen ustedes las experiencias en el mercado laboral internacional de un gerente sueco y de uno irani, o las condiciones en que se desenvuelven un exportador de Bangladesh y uno canadiense. Comparen la facilidad con que un centro vacacional del montón pero de un pais hien cotizado logra excelente cobertura mediática y la preferencia de los famosos, por un lado, con las dificultades yue tiene un destino turistico inexplorado y único en su especic, pero que se ubica en un país de débil o mala reputación. Comparen la forma en que el consumidor europeo o norteamericano está dispuesto a pagar más por un producto japonés desconocido que por un equivalente coreano idénticoy que probablemente viene de la misma factoria shina. Comparen la cobertura positiva que la prensa internacional le concederá a una política comán y corriente de un pais gue se percibe como justo, rico y estable, con el silencio 
mediático o la áspera crítica con que se recibe una política pública valiente, innovadora y audaz pero que viene de un país que arrastra una imagen negativa.

En breve, sin duda que los paises deben tener una imagen de marca y que esa imagen es fundamental para salir a competir con éxito por productos, comercio, servicios, talento, finanzas, inversiones, cultura, respeto y perfil. El problema empieza cuando en lugar de hablar de la marca que se tiene, se empieza a hablar de crear una marca.

Para muchos gobiernos, la vida sería ciertamente más fácil si les fuera posible controlar su marca pais. Para alcanzar la competitividad económica y política, bastaría con tener un buen presupuesto de marketing y contratar a las mejores agencias de marketing y relaciones públicas. Pero la realidad es mucho más compleja que eso: la imagen nacional no se crea ni se modifica a través del marketing comunicacional.

Se podría entonces preguntar: si el marketing comunicacional es tan eficaz para promover productos y servicios, ¿por qué no podría también funcionar con los países y las ciudades?

La respuesta es muy simple: el marketing no funciona muy bien con los productos y servicios, al menos no de la forma que supone el que mira desde afuera. Si bien es cierto que la buena publicidad, los bonitos logos y las slogans memorables son todos factores que se asocian a las grandes marcas comerciales, no son la razón de su éxito: una marca se hace potente cuando el producto que representa se gana la confianza del público. Ello ocurre después de un gran número de v'entas, de muchas experiencias personales a nivel del consumidor y con un producto que iguala o supera toda expectativa. Lo que las campañas publicitarias generan son ventas y su aporte a crear la marca es sólo indirecto.

Pero dado que los países no están en venta, las campañas de marketing que se hagan para promovertos son solo propaganda hueca: en lugar de decirle al público "por favor, pruebe este producto", le dicen "por favor, cambie de opinión respecto de mi pais", y es ahi donde el mensaje sale por la culata.

En el ámbito comercial, la gestión de marcas funciona únicamente porcue la empresa propietaria controla estrechamente tanto el producto como los canales de comunicación, de modo tal que puede incidir directamente sobre la experiencia del consumidor con el producto y sobre cómo se le presenta a través de los medios. Una buena empresa con un buen producto puede, con habilidad, paciencia y recursos suficientes, construir la imagen de marca que quiere y necesita y que su producto merece pero -y acquí está el gran pero no más que eso, porque como dijera el célebre publicista Bill Bernbach, si el producto es malo, una gran publicidad solo hace que su fracaso sea más estrepitoso.

Con los países pasa algo totalmente diferente, porque no existe ente alguno, ni político ni de ninguna otra naturaleza, que tenga el mismo nivel de control sobre el "producto" nacional o sobre la forma en que este se comunica al mundo 
exterior. La aldea más insignificante es infinitamente más compleja, más diversa y menos unitaria que la más grande de las corporaciones transnacionales, básicamente porque la gente está ahí por razones totalmente diferentes. Los países, a diferencia del simple credo en el interés de los accionistas que aglutina a una corporación, no tienen un solo propósito unificador. Un contrato de trabajo tiene que ver con deberes, pero un contrato social tiene que ver con derechos. Por cierto, siempre ha habido jefes de Fstado que tratan de manejar sus países como si fueran una empresa y que "controlan la marca" a través del control de los canales de commicación, pero este tipo de control a través de la propaganda solo funciona en las sociedades cerradas. Una de las ventajas de la globalización es que, en un mundo con acceso a la comunicación y a los medios internacionales, el control a través de la propaganda se ha hecho prácticamente imposible.

Otra de las razones por las cuales no es fácil cambiar la imagen de un país es que se trata de un concepto muy resistente. La imagen nacional, como lo demuestran los estudios, es un fenómeno notablemente estable; es un activo más fijo que líquido. Todos encasillamos a países y ciudades con la ayuda de estereotipos que solo abandonamos cuando no nos queda otra alternativa. Para la mayoría de las personas los lugares extranjeros son de muy limitada importancia y si un español, un sudatricano o un indio dedican apenas unos momentos de cada año a pensar en Finlandia o Helsinki, no cs de extrañar que su percepción de Finlandia y Helsinki permaneza inmutable durante largos años. Además, la imagen de un país extranjero es parte integrante de la cultura de cada país: la imagen de Finlandia en Suecia y Rusia, por ejemplo, es parte de las culturas sueca y rusa, y viceversa.

El prestigio de un país no se hace; se gana. Imaginar que un fenómeno tan profundamente enraizado como este pueda ser modificado por un instrumento tan feble como el marketing es un quimera extravagante. Como dijera Sócrates, "alcanzarás buena reputación esforzandote en ser lo que quieres parecer».

Si bien ningún gobierno puede manipular la percepción que tienen de su país millones de personas en tierras lejanas, si hay tres cosas importantes que puede hacer:

- Primero, entender y hacer un seguimiento riguroso y científico de su imagen en los países y sectores que defina como prioritarios, de modo de entender con exactitud como y dónde su imagen afecta sus intereses;

- Segundo, cooperar de forma imaginativa, eficaz y abierta con el sector privado y la sociedad civil a fin de consensuar una estrategia y una narrativa nacionales es decir, el relato sobre qué es el país, hacia dónde marcha y cómo se propone alcanzar sus metas yue reflejen de forma veraz la capacidad, el genio y la voluntad de su pueblo.

- Tercero, procurar que en cada sector el país cuente con un caudal 
constante de productos, servicios, políticas e iniciativas novedosas y llamativas, lo que lo mantendrá en el centro de la atención y la admiración mundiales, demostrará la veracidad del relatopaís y acreditará que el país tiene derecho a la reputación gue su pueblo y gobierno desean para sí.

No es el marketing comunicacional sino el acercamiento con el resto del mundo lo que potencia el perfil de un país. Y a mayor visibilidad, mayor atractivo.

La idea de un país como marca no es importante únicamente porque se le considere intelectualmente atractiva. Para la mayor parte de los países, la necesidad de estudiar, entender y pensar formas de incidir sobre su renombre internacional ha dejado de ser una simple opción: o se toman las riendas del nombre internacional o se deja que lo controlen la opinión y la ignorancia públicas. Las catastróficas consecuencias de esto último las tienen más que claras los paises africanos, por ejemplo.

No todos los gobiernos o pueblos consideran la aceptación internacional como un objetivo importante, pero cuando hablamos de la imagen de un país, estamos hablando de algo más trascendente que la simple popularidad.

Los únicos tipos de gobierno que se pueden dar el lujo de hacer abstracción del concepto que la opinión pública internacional tiene de ellos son los que no se interesan en formar parte de la comunidad mundial ni quieren que su conomía, su cultura o su pueblo reciban los beneficios de los aportes y oportunidades que ofrece el resto del mundo.

En la era de la globalización, los gobiernos responsables deben aceptar que la posición del país, uno de los bienes más valiosos con que cuenta la ciudadanía, es un valor que se les entrega en custodia mientras dure su mandato. Su deher es entregarla a sus sucesores, sin importar su color político, en el mismo estado en que la recibieron, y de ser posible, mejorarla para beneficio de las futuras generaciones.

Pocos dudan que si los gobiemos del mundo valoraran su prestigio en la mitad de lo que una buena corporación valora el suyo, el mundo sería un lugar más seguro y tranquilo de lo que es hoy día. 